\title{
Retinoic acid-related orphan receptors $\alpha$ and $\gamma$ : key regulators of lipid/glucose metabolism, inflammation, and insulin sensitivity
}

\section{Anton M. Jetten*, Hong Soon Kang and Yukimasa Takeda}

Cell Biology Section, Division of Intramural Research, National Institute of Environmental Health Sciences, National Institutes of Health, Research Triangle Park, NC, USA

Edited by:

Tsuguhito Ota, Kanazawa University, Japan

\section{Reviewed by:}

Krzysztof W. Nowak, Pozan University of Life Sciences, Poland

Venu Lagishetty, University of South Florida, USA

\section{*Correspondence:}

Anton M. Jetten, Cell Biology Section, Division of Intramural Research, National Institute of Environmental Health Sciences, National Institutes of Health, 111 T.W. Alexander Drive, Research Triangle Park, NC 27709, USA

e-mail: jetten@niehs.nih.gov
Retinoic acid-related orphan receptors $\mathrm{ROR} \alpha$ and $\mathrm{ROR} \gamma$ play a regulatory role in lipid/glucose homeostasis and various immune functions, and have been implicated in metabolic syndrome and several inflammatory diseases. ROR $\alpha$-deficient mice are protected against age- and diet-induced obesity, hepatosteatosis, and insulin resistance. The resistance to hepatosteatosis in ROR $\alpha$-deficient mice is related to the reduced expression of several genes regulating lipid synthesis, transport, and storage. Adipose tissue-associated inflammation, which plays a critical role in the development of insulin resistance, is considerably diminished in ROR $\alpha$-deficient mice as indicated by the reduced infiltration of $\mathrm{M} 1$ macrophages and decreased expression of many proinflammatory genes. Deficiency in ROR $\gamma$ also protects against diet-induced insulin resistance by a mechanism that appears different from that in ROR $\alpha$ deficiency. Recent studies indicated that RORs provide an important link between the circadian clock machinery and its regulation of metabolic genes and metabolic syndrome. As ligand-dependent transcription factors, RORs may provide novel therapeutic targets in the management of obesity and associated metabolic diseases, including hepatosteatosis, adipose tissue-associated inflammation, and insulin resistance.

Keywords: retinoic acid-related orphan receptor, obesity, inflammation, adipose tissue, hepatosteatosis, diabetes, insulin-resistance, circadian rhythm

\section{INTRODUCTION}

In the past 50 years, the occurrence of obesity has greatly increased worldwide in both adults and children and has become a major health-care concern in many countries. In the United States 30\% of the population is considered obese, while more than $66 \%$ of adults and almost $17 \%$ of children and adolescents are overweight (Browning et al., 2004; Ogden et al., 2012). Obesity is associated with an increased risk of several pathologies, including type 2 diabetes, cardiovascular disease, and non-alcoholic fatty liver disease (NAFLD). Accumulating evidence indicates that networks regulating lipid metabolism and inflammation are highly integrated and play a critical role in the development of these pathologies (Hotamisligil, 2006; Donath and Shoelson, 2011; Ouchi et al., 2011; Glass and Olefsky, 2012). Obesity leads to a systemic state of low-grade inflammation, particularly involving adipose tissue, that is causally involved in the development of insulin resistance and other diseases. Blood levels of free fatty acids (FFA) are elevated in obesity and through their interaction with Tolllike receptor 4 (TLR4) FFA induce proinflammatory pathways in macrophages and other cell types that may promote insulin resistance (Samuel and Shulman, 2012). Recent studies demonstrated that retinoic acid-related orphan receptors (RORs) are among many factors that through their modulation of immune responses and lipid/glucose homeostasis regulate the development of inflammation, metabolic syndrome, and insulin resistance (Jetten, 2009; Solt and Burris, 2012).
ROR $\alpha$ AND $\gamma$ PROTEINS

The RORs alpha, beta, and gamma $(\operatorname{ROR} \alpha-\gamma$ or NR1F1-3) constitute a subfamily of nuclear receptors that function as liganddependent transcription factors (Jetten, 2004, 2009; Solt and Burris, 2012). RORs exhibit a domain structure typical of nuclear receptors and contain an $\mathrm{N}$-terminal domain, the function of which has not yet been clearly defined, a highly conserved DNAbinding domain (DBD) consisting of two zinc finger motifs, a LBD, and a hinge domain spacing the DBD and LBD. By using different promoters and/or alternative splicing each ROR gene produces several isoforms that vary only in their $\mathrm{N}$-terminal region. Some of these isoforms exhibit a distinct tissue-specific pattern of expression and control different genes and biological processes. RORs regulate transcription by binding as monomers to ROR response elements (RORE), which consist of the core sequence "AGGTCA" preceded by an A/T-rich sequence, in the regulatory region of target genes. The activation function (AF-2), localized at the $\mathrm{C}$ terminus within the LBD of RORs, is involved in the recruitment of co-activators or co-repressors that mediate the transcriptional activation or repression by RORs. Recent studies have identified a number of (ant)agonists that interact with the LBD of ROR and either activate or inhibit ROR transcriptional activity (Kallen et al., 2002; Huh and Littman, 2012; Solt and Burris, 2012). Interaction with agonists induces a conformational change in the LBD that allows release of the co-repressor complex and promotes assembly of a co-activator complex that mediates the transcriptional 
activation by ROR, while the inverse happens for antagonists. These observations not only indicated that RORs function as ligand-dependent transcription factors, but also suggested that RORs might be potential therapeutic targets to treat disease.

\section{RORS AS REGULATORS OF SEVERAL IMMUNE PROCESSES}

$\operatorname{ROR} \alpha$ and $\operatorname{ROR} \gamma$ are important regulators of several diverse immune functions. ROR $\gamma$-deficient mice lack lymph nodes and Peyer's patches indicating that it is essential for lymph node development (Kurebayashi et al., 2000; Sun et al., 2000). Recent studies demonstrated that $\mathrm{ROR} \alpha$ and the ROR $\gamma$ t isoform play a key role in T cell lineage determination (Ivanov et al., 2006; Yang et al., 2008; Jetten, 2009). The ROR $\gamma$ t isoform in particular and to a lesser extent $\operatorname{ROR} \alpha$, is required for the differentiation of naïve $\mathrm{T}$ cells into interleukin 17 (IL-17) producing T helper 17 (Th17) cells. IL-17A expression is directly regulated by RORs through their interaction with ROREs in the Il17 promoter (Yang et al., 2008). Proinflammatory Th17 cells and IL-17 have been implicated in several autoimmune diseases and other inflammatory disorders. Deficiency in ROR $\gamma$ t or both $\mathrm{ROR} \alpha / \gamma$ receptors has been shown to greatly inhibit the generation of Th17 cells and the development of experimental encephalomyelitis in mice. In addition, mice deficient in $\operatorname{ROR} \alpha$ or $\operatorname{ROR} \gamma$ displayed a diminished susceptibility to allergen-induced lung inflammation and collagen-induced arthritis (Jaradat et al., 2006; Tilley et al., 2007) and polymorphisms in $\operatorname{ROR} \alpha$ have been associated with increased susceptibility to asthma (Ramasamy et al., 2012). A recent study identified a role for $\mathrm{ROR} \alpha$ in the generation of natural helper (NH) cells (Halim et al., 2012). ROR $\alpha$-deficient, but not ROR $\gamma$-deficient, mice lack NH cells. NH cell-deficient mice generated by ROR $\alpha$-deficient bone marrow transplantation exhibited normal Th2 cell responses, but failed to develop acute lung inflammation in response to a protease allergen. These findings might at least in part explain the reduced susceptibility to allergen-induced lung inflammation in ROR $\alpha$-deficient mice (Jaradat et al., 2006).

An increased Th17 response has been reported to correlate with white adipose tissue (WAT)-associated inflammation and the development of insulin resistance in obese mice and patients (Ahmed and Gaffen, 2010; Bertola et al., 2012). Whether inhibition of Th17 differentiation plays a role in the protection ROR $\alpha$ - and $\mathrm{ROR} \gamma$-deficient mice against diet-induced insulin resistance needs further study. $\operatorname{ROR} \alpha$ or $\operatorname{ROR} \gamma$ have also been implicated in the regulation of thymopoiesis. Loss of ROR $\gamma \mathrm{t}$ results in accelerated apoptosis of double-positive thymocytes, while $\mathrm{ROR} \alpha$ deficiency significantly reduces the generation of single positive thymocytes ( Kurebayashi et al., 2000; Sun et al., 2000; Dzhagalov et al., 2004).

\section{ROR $\alpha$ IN DIET- AND AGE-INDUCED OBESITY}

Study of Staggerer ( $\left.R O R \alpha^{s g / s g}\right)$ mice, a natural mutant strain containing a deletion in the $R O R \alpha$ gene that results in loss of $\operatorname{ROR} \alpha$ expression, indicated that ROR $\alpha$ plays a critical role in the control of lipid metabolism and the development of various aspects of metabolic syndrome. These investigations showed that $R O R \alpha^{s g / s g}$ mice are protected against age- and diet-induced obesity and the development of several obesity-linked pathologies, including adipose tissue-associated inflammation, hepatosteatosis, and insulin resistance (Kang et al., 2011; Lau et al., 2011). ROR $\alpha^{s g / s g}$ mice fed a high fat diet (HFD) gain relatively less weight and exhibit a significantly lower total body fat index compared to wild-type (WT) littermates on a HFD. Similarly, male $R O R \alpha^{s g / s g}$ mice were also protected against age-induced obesity. Adipose tissue is the main site of storage of excess energy that is stored in the form of triglycerides in single large lipid droplets. The reduced adiposity in $R O R \alpha^{s g / s g}$ mice was largely related to smaller adipocyte size due to diminished deposition of triglycerides.

$\mathrm{ROR} \alpha$, particularly the ROR $\alpha 4$ isoform, has been shown to be highly expressed in WAT and to be induced during differentiation of D1 and 3T3-L1 preadipocytes (Austin et al., 1998). Overexpression of ROR $\alpha$ in preadipocytes inhibits adipocyte differentiation (Duez et al., 2009; Ohoka et al., 2009). This appears to be mediated through a direct interaction of $\mathrm{ROR} \alpha$ with CCAAT/enhancerbinding protein $\beta(\mathrm{C} / \mathrm{EBP} \beta)$ that results in the inhibition of the recruitment of the co-activator $\mathrm{CBP}$ and repression of $\mathrm{C} / \mathrm{EBP} \beta$ transcriptional activity. These studies suggest that $\mathrm{ROR} \alpha$ has a negative regulatory role in adipocyte differentiation. This function, however, does not explain the reduced adiposity observed in $\mathrm{ROR} \alpha$-deficient mice.

Obesity is a consequence of an imbalance between energy intake and expenditure (Glass and Olefsky, 2012; Samuel and Shulman, 2012). However, the decrease in diet-induced adiposity in $R O R \alpha^{s g / s g}$ mice was found not to be due to reduced food intake or increased fecal lipid excretion. Indirect calorimetric analysis showed that $\mathrm{VO}_{2}, \mathrm{VCO}_{2}$, and heat generation were significantly enhanced in $R O R \alpha^{s g / s g}$ mice on a HFD (Kang et al., 2011). This suggested that elevated energy expenditure might at least in part be responsible for the reduced weight gain and resistance to hepatosteatosis and insulin insensitivity in $R O R \alpha^{s g / s g}$ mice.

\section{ROR $\alpha$ AND WAT-ASSOCIATED INFLAMMATION}

In addition to functioning as the main site of storage of extra energy in the form of triglycerides derived from food intake, white adipocytes produce a variety of endocrine hormones, including leptin, adiponectin, resistin, and retinol-binding protein 4 (RBP4) which regulate food intake, lipid metabolism, and inflammation (Hotamisligil, 2006; Guilherme et al., 2008; Glass and Olefsky, 2012). Leptin and adiponectin promote insulin sensitivity, while resistin and RBP4 have the opposite effect and impair insulin sensitivity. It is now well-recognized that obesity is associated with a chronic state of low grade, systemic inflammation and that this is an important contributory factor in the development of insulin resistance (Hotamisligil, 2006; Odegaard and Chawla, 2008; Nishimura et al., 2009; Glass and Olefsky, 2012). Progressive infiltration of various immune cells, including macrophages and $\mathrm{CD}^{+}$effector $\mathrm{T}$ lymphocytes, in WAT lead to increased release of proinflammatory cyto- and chemokines. In addition to the accumulation of bone marrow-derived macrophages, there is also a shift from anti-inflammatory "alternatively activated" (CD11c- CD206 ${ }^{+}$) M2 macrophages to proinflammatory "classically activated" (CD11c ${ }^{+}$CD206 $\left.{ }^{-}\right)$M1 macrophages (Sun et al., 2011; Glass and Olefsky, 2012), which in advanced obesity aggregate into crown-like structures (CLS) surrounding necrotic adipocytes. Recent studies indicated that $\mathrm{CD}^{+} \mathrm{T}$ cells are critical in promoting recruitment of macrophages in WAT in obesity (Weisberg et al., 2003; Odegaard and Chawla, 2008; Nishimura 
et al., 2009). In addition, a reduction in anti-inflammatory $\mathrm{T}$ regulatory (Treg) cells and an increase in proinflammatory Th17 response further stimulate WAT-associated inflammation (Figure 1).

Deficiency of $\operatorname{ROR} \alpha$ greatly inhibits diet-induced adipose tissue-associated inflammation in mice (Kang et al., 2011; Lau et al., 2011). This is indicated by the greatly reduced infiltration of macrophages and $\mathrm{CD}^{+} \mathrm{T}$ lymphocytes in WAT of $R O R \alpha^{s g / s g}$ mice fed a HFD. This was further supported by the significant reduction in the formation of CLS and the expression of several macrophage markers, such as F4/80, Mac-2, macrophage expressed 1 (Mpeg1), and macrophage scavenger receptor 1 (Msr1), in WAT of $R O R \alpha^{s g / s g}$ mice. Moreover, the relative percentage of proinflammatory M1 macrophages was significantly diminished in $R O R \alpha^{s g / s g}$ WAT. This was supported by flow cytometric analysis and the much lower levels of Cd11c expression. The reduced inflammation in $R O R \alpha^{s g / s g}$ WAT is further indicated by gene expression profiling showing a greatly reduced expression of a large number of chemokines, including $\mathrm{Ccl} 2, \mathrm{Ccl} 8, \mathrm{Ccl} 3$, and $\mathrm{Ccl}$, the chemokine receptors $\mathrm{Ccr} 3, \mathrm{Ccr} 5$, and $\mathrm{Ccr} 7$, the proinflammatory cytokines $T n f \alpha$ and $I L-6$, the interleukin 1 receptor antagonist (Il1rn), osteopontin (Opn), CD44, serum amyloid 3 (Saa3), and several TLRs and metalloproteinases in WAT of $R O R \alpha^{s g / s g}$ mice compared to their WT counterparts (Kang et al., 2011). The expression of these genes has been reported to be elevated in obesity and many of these genes have been implicated in obesity-induced inflammation in WAT as well as insulin resistance. For example, both the CCL2/CCR2 and CCL3/CCR5 pathways have been reported to promote recruitment of macrophages in adipose tissue (Kanda et al., 2006; Kitade et al., 2012). CD44, a multifunctional cell membrane protein that acts as a receptor for hyaluronan and Opn, has been shown to regulate migration of macrophages and neutrophils (Johnson and Ruffell, 2009). CD44 and Opn null mice are protected against the development of HFD-induced hepatosteatosis, WAT-associated inflammation, and insulin resistance (Nomiyama et al., 2007; Bertola et al., 2009; Kiefer et al., 2011; Kodama et al., 2012). These observations suggest that suppression of several proinflammatory genes and pathways in $R O R \alpha^{s g / s g}$ WAT is causally linked to the reduced inflammation (Figure 1). Future studies have to determine what the primary effects are by which $\mathrm{ROR} \alpha$ regulate the expression of these genes.

\section{ROR $\alpha$ AND HEPATOSTEATOSIS}

Obesity is associated with increased prevalence of NAFLD, which is characterized by elevated lipid accumulation in hepatocytes (Fabbrini et al., 2010). NAFLD develops when the rate of fatty acid uptake and synthesis and subsequent esterification to triglycerides is greater than the rate of fatty acid oxidation and secretion. Advanced NAFLD progresses into increased inflammation and hepatotoxicity. Several studies showed that compared to WT mice hepatic triglyceride levels are considerably reduced in $R O R \alpha^{s g} / s g$ mice fed a HFD or aging male $R O R \alpha^{s g / s g}$ mice (Raspe et al., 2001; Lau et al., 2008; Kang et al., 2011). These observations indicated that $R O R \alpha^{s g / s g}$ mice are protected against the development of age- and diet-induced hepatosteatosis. Gene expression profiling revealed that the expression of a number of lipogenic genes was

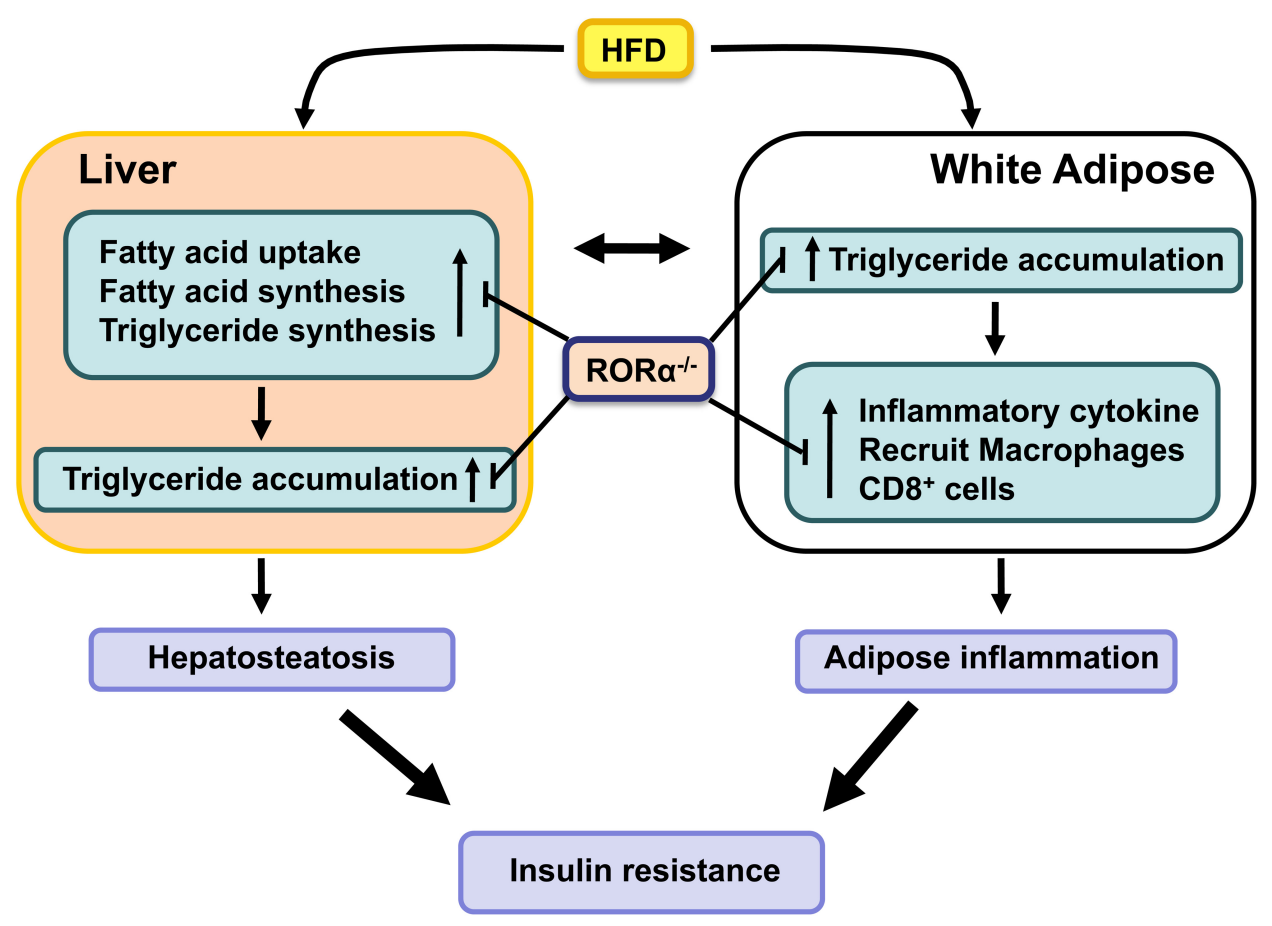

FIGURE 1 | ROR $\alpha$ functions as a positive regulator of hepatosteatosis, WAT-associated inflammation, and insulin-resistance in diet- and age-induced obesity. Loss of ROR $\alpha$ inhibits the hepatic expression of lipogenic genes and suppresses the expression of proinflammatory genes and the infiltration of macrophages in WAT, and as a result protects against these pathologies. 
significantly reduced in the liver of $R O R \alpha^{s g} / s g$ mice fed a HFD. Expression of Srebp-1c and fatty acid synthase (Fas), key regulators for lipogenesis, was reduced in liver of $R O R \alpha^{s g / s g}$ mice. In addition, the expression of several genes involved in the main pathway of triglyceride synthesis, including glycerol-3-phosphate acyltransferase (Gpam or Gpat1) and acyl-glycerol-3-phosphate acyltransferase 9 (Agpat9) and Mogat1, which is part of an alternative pathway of triglyceride synthesis, were significantly diminished in $R O R \alpha^{s g / s g}$ liver (Kang et al., 2011). The hepatic expression of the cell death-inducing DFFA-like effectors a and c (Cidea and Cidec) and perilipin 2 (Plin2 or Adfp), which play a critical role in the regulation of lipid storage, lipid droplet formation, and lipolysis (Gong et al., 2009; Greenberg et al., 2011), was also suppressed in $R O R \alpha$-deficient mice. ROR $\alpha$ has been reported to activate Plin2 transcription directly through interaction with ROREs in the Plin2 promoter (Kang et al., 2011). Recently, the expression of fibroblast growth factor ( $F g f 21)$, an important regulator of lipid/glucose metabolism, was found to be directly regulated by ROR $\alpha$ in hepatocytes (Wang et al., 2010c). Together these observations suggest that the protection against hepatosteatosis in $R O R \alpha^{s g / s g}$ mice is related to reduced expression of many genes involved in promoting lipogenesis and triglyceride storage, some of which are directly regulated by ROR $\alpha$ (Figure 1).

\section{ROR $\alpha$ AND INSULIN RESISTANCE}

Both adipose-associated inflammation and hepatosteatosis have been linked to the pathogenesis of insulin resistance in obesity (Guilherme et al., 2008; Donath and Shoelson, 2011; Samuel and Shulman, 2012), although a cause-effect relationship not always exists between hepatosteatosis and diabetes (Sun and Lazar, 2013). The phenotypic differences observed between WT and $R O R \alpha^{s g / s g}$ mice fed a HFD are consistent with this correlation. $R O R \alpha^{s g / s g}$ mice, which are protected against obesity, hepatosteatosis, and WAT-associated inflammation, exhibited a significantly reduced susceptibility to diet-induced insulin resistance and glucose intolerance compared to obese WT mice (Lau et al., 2008; Kang et al., 2011). In humans, two studies have revealed a connection between ROR $\alpha$, obesity, and type 2 diabetes. A rearrangement resulting in disruption of human ROR $\alpha 1$ was found to be associated with severe obesity (Klar et al., 2005), while a recent GWAS study showed an association between a single nucleotide polymorphism in ROR $\alpha$ (rs7164773) and increased risk for type 2 diabetes in the Mexico Mestizo population (Gamboa-Melendez et al., 2012).

Many inflammatory and lipogenic genes, including Plin2, Ill rn, $O p n, C D 44$, and Cidec, that are down-regulated in $R O R \alpha^{s g / s g}$ mice have been reported to also regulate insulin sensitivity. Plin2 null mice displayed reduced hepatic lipid accumulation and improved insulin sensitivity and glucose tolerance in an ob/ob background (Chang et al., 2010). Il1rn, one of the genes most dramatically repressed in WAT of $R O R \alpha^{s g / s g}$ mice (Kang et al., 2011), has been reported to be highly up-regulated in WAT of obese humans and to regulate insulin sensitivity (Juge-Aubry et al., 2003; Somm et al., 2006). Similarly, Opn expression was found to be elevated in obesity, while Opn deficiency was shown to inhibit obesity-induced inflammation and insulin resistance (Bertola et al., 2009; Kiefer et al., 2011). Deficiency in CD44, a receptor for Opn, also results in improved insulin sensitivity (Kodama et al., 2012) suggesting a role for the Opn/CD44 pathway in the control of insulin sensitivity. Mice deficient in Cidea or Cidec, which play a role in lipid storage, are protected from diet-induced obesity and display improved insulin sensitivity (Gong et al., 2009). Thus, the downregulation of several genes, including Plin2, Illrn, Opn, CD44, and Cidec in $R O R \alpha^{s g / s g}$ mice may collaboratively be responsible for the improved insulin sensitivity through their interrelated effects on inflammation, adipogenesis, and lipid homeostasis (Figure 1).

In addition to adipose tissue and liver, the pancreas and the skeletal muscle also play important roles in energy homeostasis and insulin resistance. The pancreatic islets produce a number of hormones, including insulin and glucagon, that are critical in the regulation of lipid and glucose homeostasis (Saltiel and Kahn, 2001; Cryer, 2012). ROR $\alpha$ was shown to be selectively expressed in the glucagon-producing alpha cells; however, its role in these cells and its relationship to the phenotype observed in ROR $\alpha$-deficient mice needs yet to be established (Mühlbauer et al., 2013). In skeletal muscle, ROR $\alpha$ has been reported to regulate the expression of a number of genes involved in lipid and carbohydrate metabolism (Lau et al., 2011). Ectopic expression of an ROR $\alpha$ mutant in skeletal muscle $\mathrm{C} 2 \mathrm{C} 12$ cells reduced the expression of the lipogenic genes, sterol regulatory element-binding transcription factor 1 (Srebp1), Fas, and stearoyl-CoA desaturase 1 (Scd1), and genes involved in cholesterol efflux, such as ATP-binding cassette, subfamily A, member 1 (Abca1). Caveolin-3 (Cav3) and carnitine palmitoyltransferase-1 (Cpt1) were found to be directly regulated by ROR $\alpha$. Changes in the expression of these genes may be in part responsible for the modulation of lipid and glucose homeostasis by $\operatorname{ROR} \alpha$.

In muscle, insulin stimulates glucose uptake by stimulating the translocation of Glut4 (Slc2a4) to the plasma membrane (Rose and Richter, 2005). This involves phosphorylation of the insulin receptor substrate 1 (IRS1), which leads to the activation of phosphatidylinositol 3-kinase (PI3K) and subsequently AKT, which then promotes Glut4 translocation. Recently, evidence was provided for a role of ROR $\alpha$ in PI3K-Akt signaling (Lau et al., 2011). Akt1/2 expression was up-regulated in skeletal muscle of $R O R \alpha^{s g / s g}$ mice and this correlated with an increase in the level of insulin-induced Akt phosphorylation, Glut4 expression, and glucose uptake. This stimulation in Akt signaling might at least in part account for the improved insulin sensitivity observed in $R O R \alpha^{s g / s g}$ mice.

\section{ROR 1 AND INSULIN SENSITIVITY}

The ROR $\gamma$ gene generates two different isoforms, $\operatorname{ROR} \gamma 1$ and ROR $\gamma$ t (ROR $\gamma 2)$, that are expressed in a highly tissue-specific manner (Jetten, 2009). Expression of the ROR $\gamma 1$ isoform is restricted to several peripheral tissues, including liver, adipose tissue, kidney, small intestines, pancreas, and skeletal muscle. Recent studies identified ROR $\gamma 1$ as a negative regulator of adipocyte differentiation and a modulator of obesity-associated insulin resistance (Meissburger et al., 2011; Tinahones et al., 2012). In obese $R O R \gamma^{-1-}$ mice, the number of adipocytes was increased (hyperplasia), while adipocyte size was reduced. Fasting blood insulin levels were shown to be significantly lower in diet-induced obese 
$R O R \gamma^{-/-}$mice and in $R O R \gamma^{-/-} o b / o b$ double knockout mice and mice displayed improved insulin sensitivity. In addition, $R O R \gamma^{-/-}$adipocytes were highly insulin sensitive leading to improved control of circulating FFA. These observations are consistent with a recent study showing that, opposed to adipose hypertrophy, obese patients with adipose tissue hyperplasia (many small adipocytes) exhibit better glucose and lipid profiles and might be less susceptible to developing insulin resistance (Hoffstedt et al., 2010) and with data showing that in human patients the level of $R O R \gamma 1$ expression positively correlated with adipocyte size and insulin resistance (Meissburger et al., 2011; Tinahones et al., 2012). Up to now, no association has been established between $R O R \gamma$ polymorphisms and susceptibility to insulin resistance in humans. However, in cattle, a single polynucleotide polymorphism in ROR $\gamma$ has been linked to increased adiposity (Barendse et al., 2007). These observations suggest that the loss or potentially the inhibition of ROR $\gamma 1$ might protect against insulin resistance and type 2 diabetes.

In addition to adipose tissue, regulation of lipid and glucose metabolism in other tissues, including liver, pancreas, and skeletal muscle might be part of the mechanism by which by ROR $\gamma$ modulates insulin sensitivity. In skeletal muscle, $\operatorname{ROR} \gamma$ has been reported to regulate the expression of genes associated with lipid and carbohydrate metabolism as well as the production of reactive oxygen species (Raichur et al., 2007). A recent study revealed that $\operatorname{ROR} \gamma$ was selectively expressed in insulin-producing pancreatic $\beta$ cells; however, its role in $\beta$ cells and how this relates to the modulation of insulin sensitivity by $\operatorname{ROR} \gamma$ has yet to be established (Mühlbauer etal., 2013). Further study is required to understand the modulation of lipid/glucose homeostasis and insulin sensitivity by $\operatorname{ROR} \gamma$.

\section{CONNECTION BETWEEN RORS, CIRCADIAN RHYTHM, AND METABOLIC SYNDROME}

It has been well established that many behavioral and physiological activities display circadian rhythms that are regulated by endogenous clocks (Asher and Schibler, 2011; Bass, 2012; Mohawk et al., 2012). At the molecular level the clockwork consists of an integral network of several interlocking positive and negative transcriptional and translational feedback loops that include the transcriptional regulators brain and muscle ARNT-like 1 (Bmal1), neuronal PAS domain protein 2 (Npas2), circadian locomotor output cycles kaput (Clock), two cryptochrome proteins (Cry1, 2), the nuclear receptors Rev-erb $\alpha$ and $-\beta, \mathrm{E} 4$ promoter-binding protein 4 (E4bp4), and three period proteins (Per1-3).

Accumulating evidence suggests that disruption of circadian rhythm is closely associated with several pathologies, including sleep disorders, cancer and metabolic syndrome (Maury et al., 2010). Recent studies have established a strong link between the circadian clock machinery and the regulation of a number of metabolic pathways (Asher and Schibler, 2011; Bass, 2012). Bmal1, Clock, and Cryl have been implicated in the regulation of glucose homeostasis and dysfunction in these proteins lead to impaired glucose tolerance (Rudic et al., 2004; Zhang et al., 2010). Hepatic overexpression of Cryl has been reported to improve insulin-sensitivity in insulin-resistant $d b / d b$ mice (Zhang et al., 2010). In addition, circadian oscillator components, such as Cry1, have been implicated in the regulation of immune responses (Castanon-Cervantes et al., 2010; Logan and Sarkar, 2012; Narasi-

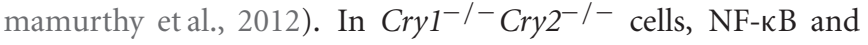
protein kinase A (PKA) signaling pathways are constitutively activated resulting in elevated levels of circulating $\mathrm{TNF} \alpha, \mathrm{Il}-1 \beta$, and Il-6 (Narasimamurthy et al., 2012).

A number of studies demonstrated that RORs play a role in the modulation of circadian behavior and clock gene expression ( Sato et al., 2004; Ueda et al., 2005; Duez and Staels, 2010; Figure 2). Bmal1, Npas2, E4bp4, and Cry1 transcription are directly regulated by $\operatorname{ROR} \gamma$ and $\operatorname{ROR} \alpha$ in several peripheral tissues through their interaction with ROREs in their regulatory regions (Crumbley et al., 2010; Takeda et al., 2011, 2012). ROR $\gamma 1$ appears to be the major ROR isotype modulating the circadian expression of clock genes in peripheral tissues. ROR $\gamma 1$ itself exhibits a strong oscillatory pattern of expression in several peripheral tissues, including kidney, liver, pancreas, and adipose tissue, while ROR $\alpha$ exhibits only a weak circadian expression pattern (Mongrain et al., 2008; Takeda et al., 2012; Mühlbauer et al., 2013). The ROR $\gamma 1$ gene is directly regulated by Bmal1/Clock heterodimers which interact with two successive E-boxes in the ROR $\gamma 1$ promoter (Mongrain et al., 2008; Takeda et al., 2012). Recent studies have suggested that ROR $\gamma 1$ and ROR $\alpha$ might provide a link between the clock machinery and their regulation of metabolic genes (Takeda et al., 2012; Figure 2). Data demonstrating that the circadian pattern of expression of a number of metabolic genes are regulated by clock proteins and RORs and observations showing that circadian expression of $\operatorname{ROR} \gamma 1$ is controlled by the clock machinery suggested that RORs might function as downstream mediators in the mechanism by which clock proteins regulate the circadian expression of

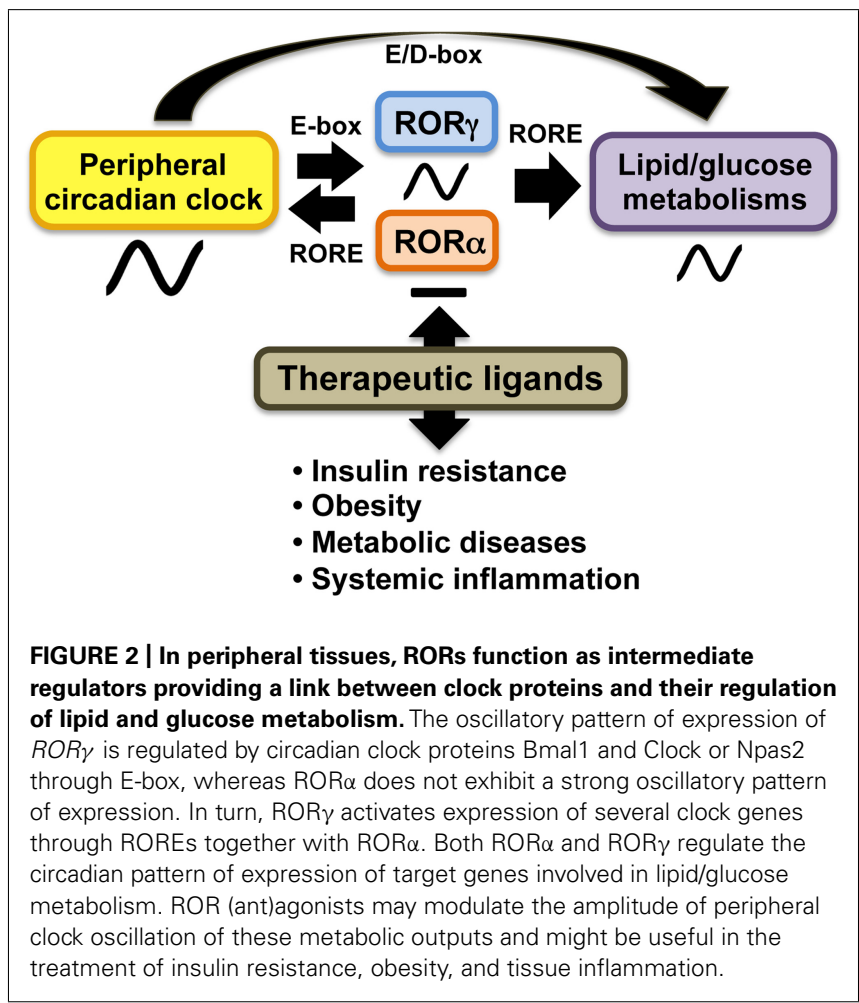


metabolic genes (Sato etal., 2004; Akashi and Takumi, 2005; Guillaumond etal., 2005; Ueda etal., 2005; Crumbley etal., 2010; Duez and Staels, 2010; Takeda et al., 2011, 2012). This is supported by observations showing that RORs regulate the circadian pattern of expression of a number of genes involved in the lipid/glucose homeostasis, including Plin2, sulfotransferase Sul1E1, the vasopressin receptor Avpr1a, and citrate synthase (CS), which exhibit roles in lipogenesis, glycogenolysis, and/or cholesterogenesis (Kang et al., 2007; Crumbley et al., 2012; Takeda et al., 2012). Thus, RORs appear to be part of the mechanism that links the circadian clock to its regulation of lipid/glucose homeostasis, inflammation, and insulin resistance (Figure 2).

\section{RORS AS THERAPEUTIC TARGETS FOR METABOLIC SYNDROME AND INSULIN RESISTANCE}

X-ray crystallography studies of the LBD of ROR $\alpha$ identified the presence of cholesterol in the ligand-binding pocket of ROR $\alpha$ (Kallen et al., 2002). Subsequent studies identified cholesterol sulfate, 7-dehydrocholesterol, and 25-hydroxycholesterol as ROR $\alpha$ agonists (Kallen et al., 2004). All-trans retinoic acid and the synthetic retinoid, ALRT 1550 were reported to bind and function as antagonists for $\operatorname{ROR} \beta$ and $\operatorname{ROR} \gamma$, but not ROR $\alpha$ (Stehlin-Gaon et al., 2003). Recently, ursolic acid and several oxygenated sterols, including $7 \alpha$-hydroxycholesterol (7 $\alpha$-OHC), 7 $\beta$-hydroxycholesterol, 7-ketocholesterol, and 24Shydroxycholesterol, were shown to function as inverse agonists to both ROR $\alpha$ and ROR $\gamma$ (Wang etal., 2010a; Xu et al., 2011), while 20 $\alpha$-hydroxycholesterol and 22R-hydroxycholesterol acted as agonists (Jin etal., 2010). The LXR agonist T0901317 and several other synthetic derivatives, including SR1001, were identified as ROR $\alpha$ and ROR $\gamma$ inverse agonists. Digoxin and several derivatives were identified as specific inhibitors for $\operatorname{ROR} \gamma$ transcriptional activity (Fujita-Sato etal., 2011; Huh etal., 2011). The ROR (inverse) antagonists have been reported to repress the expression of ROR target genes and the activation of their promoter regulatory region by inhibiting the recruitment of coactivators. Moreover, ROR antagonists have been shown to inhibit Th17 cell differentiation and IL-17 production both in vitro and in vivo and to suppress the development of experimental autoimmune encephalomyelitis (Huh et al., 2011; Jetten, 2011;

\section{REFERENCES}

Ahmed, M., and Gaffen, S. L. (2010). IL-17 in obesity and adipogenesis. Cytokine Growth Factor Rev. 21, 449453.

Akashi, M., and Takumi, T. (2005). The orphan nuclear receptor $\mathrm{ROR} \alpha$ regulates circadian transcription of the mammalian core-clock Bmal1. Nat. Struct. Mol. Biol. 12, 441-448.

Asher, G., and Schibler, U. (2011). Crosstalk between components of circadian and metabolic cycles in mammals. Cell Metab. 13, 125-137.

Austin, S., Medvedev, A., Yan, Z. H., Adachi, H., Hirose, T., and Jetten, A. M. (1998). Induction of the nuclear orphan receptor $\operatorname{ROR} \gamma$

Solt et al., 2011). Therefore, antagonists for ROR $\gamma$ might be potential drugs for pharmacological intervention in the treatment and suppression of several autoimmune diseases, including multiple sclerosis, collagen-induced arthritis, rheumatoid arthritis, and asthma (Solt etal., 2010; Huh and Littman, 2012). Because of their role in regulating various features of metabolic syndrome, $\operatorname{ROR} \alpha$ and $\gamma$ antagonists might also have beneficial effects in the management of obesity and insulin resistance.

\section{SUMMARY}

The study of ROR-deficient mice has clearly demonstrated that $\mathrm{ROR} \alpha$ and ROR $\gamma$ are important in several physiological processes, including the regulation of several immune responses, lipid/glucose homeostasis, and circadian rhythm. These studies revealed that loss of ROR $\alpha$ protects against the development of diet- and age-induced obesity, hepatosteatosis, glucose intolerance, and insulin resistance, while loss of $\mathrm{ROR} \gamma$ protects against insulin resistance. These protective effects have been linked to suppression of the expression of multiple proinflammatory and metabolic genes. RORs regulate expression of some of these genes directly by binding ROREs in their regulatory region and in certain cases involves changes in their circadian pattern of expression. Although much progress has been made, what event or which ROR target genes are the primary driving force by which RORs influences WAT-associated inflammation, hepatosteatosis, and insulin resistance needs further study. With the increasing evidence for an interrelationship between the controls of lipid/glucose metabolism, inflammation and circadian rhythm, RORs might functions as intermediaries between the controls. With the discovery of ROR antagonists, RORs may provide a novel therapeutic target in the management of various aspect of metabolic syndrome.

\section{ACKNOWLEDGMENTS}

The authors would like to thank Drs Kristin Lichti-Kaiser and Gary ZeRuth for their comments on the manuscript. This research was supported by the Intramural Research Program of the National Institute of Environmental Health Sciences, the National Institutes of Health [Z01-ES-101586].

Bertola, A., Deveaux, V., Bonnafous, S., Rousseau, D., Anty, R., Wakkach, A., et al. (2009). Elevated expression of osteopontin may be related to adipose tissue macrophage accumulation and liver steatosis in morbid obesity. Diabetes 58, 125-133.

Browning, J. D., Szczepaniak, L. S., Dobbins, R., Nuremberg, P., Horton, J. D., Cohen, J. C., et al. (2004). Prevalence of hepatic steatosis in an urban population in the United States: impact of ethnicity. Hepatology 40, 1387-1395. Castanon-Cervantes, O., Wu, M., Ehlen, J. C., Paul, K., Gamble, K. L., Johnson, R. L., et al. (2010). Dysregulation of inflammatory responses by chronic circadian disruption. J. Immunol. 185, 5796-5805.
Chang, B. H., Li, L., Saha, P., and Chan, L. (2010). Absence of adipose differentiation related protein upregulates hepatic VLDL secretion, relieves hepatosteatosis, and improves whole body insulin resistance in leptindeficient mice. J. Lipid Res. 51, 21322142.

Crumbley, C., Wang, Y., Banerjee, S., and Burris, T. P. (2012). Regulation of expression of citrate synthase by the retinoic acid receptor-related orphan receptor $\alpha(\operatorname{ROR} \alpha)$. PLoS ONE 7:e33804. doi: 10.1371/journal.pone.0033804

Crumbley, C., Wang, Y., Kojetin, D. J., and Burris, T. P. (2010). Characterization of the core mammalian clock component, NPAS2, as a 
REV-ERB $\alpha /$ ROR $\alpha$ target gene. J. Biol. Chem. 285, 35386-35392.

Cryer, P. E. (2012). Minireview: glucagon in the pathogenesis of hypoglycemia and hyperglycemia in diabetes. Endocrinology 153, 10391048.

Donath, M. Y., and Shoelson, S. E. (2011). Type 2 diabetes as an inflammatory disease. Nat. Rev. Immunol. $11,98-107$.

Duez, H., Duhem, C., Laitinen, S., Patole, P. S., Abdelkarim, M., BoisJoyeux, B., et al. (2009). Inhibition of adipocyte differentiation by ROR $\alpha$. FEBS Lett. 583, 2031-2036.

Duez, H., and Staels, B. (2010). Nuclear receptors linking circadian rhythms and cardiometabolic control. Arterioscler. Thromb. Vasc. Biol. 30, 1529 1534.

Dzhagalov, I., Giguere, V., and $\mathrm{He}$, Y. W. (2004). Lymphocyte development and function in the absence of retinoic acid-related orphan receptor

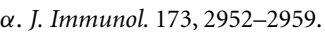

Fabbrini, E., Sullivan, S., and Klein, S. (2010). Obesity and nonalcoholic fatty liver disease: biochemical, metabolic, and clinical implications. Hepatology 51, 679-689.

Fujita-Sato, S., Ito, S., Isobe, T., Ohyama, T., Wakabayashi, K., Morishita, K., et al. (2011). Structural basis of digoxin that antagonizes ROR $\gamma t$ receptor activity and suppresses Th17 cell differentiation and interleukin (IL)-17 production. I. Biol. Chem. 286, 31409-31417.

Gamboa-Melendez, M. A., HuertaChagoya, A., Moreno-Macias, H., Vazquez-Cardenas, P., OrdonezSanchez, M. L., Rodriguez-Guillen, R., etal. (2012). Contribution of common genetic variation to the risk of type 2 diabetes in the mexican mestizo population. Diabetes 61 , 3314-3321.

Glass, C. K., and Olefsky, J. M. (2012). Inflammation and lipid signaling in the etiology of insulin resistance. Cell Metab. 15, 635-645.

Gong, J., Sun, Z., and Li, P. (2009). CIDE proteins and metabolic disorders. Curr. Opin. Lipidol. 20, 121-126.

Greenberg, A. S., Coleman, R. A., Kraemer, F. B., McManaman, J. L., Obin, M. S., Puri, V., et al. (2011). The role of lipid droplets in metabolic disease in rodents and humans. J. Clin. Invest. 121, 2102-2110.

Guilherme, A., Virbasius, J. V., Puri, V., and Czech, M. P. (2008). Adipocyte dysfunctions linking obesity to insulin resistance and type 2 diabetes. Nat. Rev. Mol. Cell Biol. 9, 367-377.
Guillaumond, F., Dardente, H., Giguere, V., and Cermakian, N. (2005). Differential control of Bmall circadian transcription by REV-ERB and ROR nuclear receptors. J. Biol. Rhythms 20, 391-403.

Halim, T. Y., MacLaren, A., Romanish, M. T., Gold, M. J., McNagny, K. M., and Takei, F. (2012). Retinoicacid-receptor-related orphan nuclear receptor $\alpha$ is required for natural helper cell development and allergic inflammation. Immunity 37 , 463-474.

Hoffstedt, J., Arner, E., Wahrenberg, H., Andersson, D. P., Qvisth, V., Lofgren, P., et al. (2010). Regional impact of adipose tissue morphology on the metabolic profile in morbid obesity. Diabetologia 53, 2496-2503.

Hotamisligil, G. S. (2006). Inflammation and metabolic disorders. Nature 444, 860-867.

Huh, J. R., Leung, M. W., Huang, P., Ryan, D. A., Krout, M. R., Malapaka, R. R., etal. (2011). Digoxin and its derivatives suppress TH17 cell differentiation by antagonizing ROR $\gamma$ activity. Nature 472 , 486-490.

Huh, J. R., and Littman, D. R. (2012) Small molecule inhibitors of ROR $\gamma \mathrm{t}$ : targeting Th17 cells and other applications. Eur. J. Immunol. 42, 22322237.

Ivanov, I. I., McKenzie, B. S., Zhou, L., Tadokoro, C. E., Lepelley, A., Lafaille, J. J., et al. (2006). The orphan nuclear receptor ROR $\gamma$ directs the differentiation program of proinflammatory IL-17+ Thelper cells. Cell 126, 11211133.

Jaradat, M., Stapleton, C., Tilley, S. L., Dixon, D., Erikson, C. J., McCaskill, J. G., et al. (2006). Modulatory role for retinoid-related orphan receptor $\alpha$ in allergen-induced lung inflammation. Am. J. Respir. Crit. Care Med. 174, 1299-1309.

Jetten, A. M. (2004). Recent advances in the mechanisms of action and physiological functions of the retinoidrelated orphan receptors (RORs). Curr. Drug Targets Inflamm. Allergy 3, 395-412.

Jetten, A. M. (2009). Retinoid-related orphan receptors (RORs): critical roles in development, immunity, circadian rhythm, and cellular metabolism. Nucl. Recept. Signal. 7, e003.

Jetten, A. M. (2011). Immunology: a helping hand against autoimmunity. Nature 472, 421-422.

Jin, L., Martynowski, D., Zheng, S., Wada, T., Xie, W., and Li, Y. (2010). Structural basis for hydroxycholesterols as natural ligands of orphan nuclear receptor ROR $\gamma$. Mol. Endocrinol. 24, 923-929.

Johnson, P., and Ruffell, B. (2009). CD44 and its role in inflammation and inflammatory diseases. Inflamm. Allergy Drug Targets 8, 208-220.

Juge-Aubry, C. E., Somm, E., Giusti, V., Pernin, A., Chicheportiche, R., Verdumo, C., et al. (2003). Adipose tissue is a major source of interleukin-1 receptor antagonist: upregulation in obesity and inflammation. Diabetes 52, 1104-1110.

Kallen, J., Schlaeppi, J. M., Bitsch, F., Delhon, I., and Fournier, B. (2004) Crystal structure of the human ROR $\alpha$ ligand binding domain in complex with cholesterol sulfate at $2.2 \mathrm{~A}$. $J$. Biol. Chem. 279, 14033-14038.

Kallen, J. A., Schlaeppi, J. M., Bitsch, F., Geisse, S., Geiser, M., Delhon, I., et al. (2002). X-ray structure of the hROR $\alpha$ LBD at $1.63 \mathrm{~A}$ : structural and functional data that cholesterol or a cholesterol derivative is the natural ligand of ROR $\alpha$. Structure 10, 1697-1707.

Kanda, H., Tateya, S., Tamori, Y., Kotani, K., Hiasa, K., Kitazawa, R., et al. (2006). MCP-1 contributes to macrophage infiltration into adipose tissue, insulin resistance, and hepatic steatosis in obesity. J. Clin. Invest. 116, 1494-1505.

Kang, H. S., Angers, M., Beak, J. Y., Wu, X., Gimble, J. M., Wada, T., et al. (2007). Gene expression profiling reveals a regulatory role for ROR $\alpha$ and ROR $\gamma$ in phase I and phase II metabolism. Physiol. Genomics 31 281-294.

Kang, H. S., Okamoto, K., Takeda, Y., Beak, J. Y., Gerrish, K., Bortner, C. D., et al. (2011). Transcriptional profiling reveals a role for ROR $\alpha$ in regulating gene expression in obesityassociated inflammation and hepatic steatosis. Physiol. Genomics 43, 818-828.

Kiefer, F. W., Neschen, S., Pfau, B., Legerer, B., Neuhofer, A., Kahle, M. et al. (2011). Osteopontin deficiency protects against obesity-induced hepatic steatosis and attenuates glucose production in mice. Diabetologia 54 , 2132-2142.

Kitade, H., Sawamoto, K., Nagashimada, M., Inoue, $\mathrm{H}$., Yamamoto, Y., Sai, Y., et al. (2012). CCR5 plays a critical role in obesityinduced adipose tissue inflammation and insulin resistance by regulating both macrophage recruitment and M1/M2 status. Diabetes 61, 1680-1690.

Klar, J., Asling, B., Carlsson, B., Ulvsback, M., Dellsen, A., Strom, C., et al. (2005). RAR-related orphan receptor $\mathrm{A}$ isoform $1(\mathrm{ROR} \alpha 1)$ is disrupted by a balanced translocation $\mathrm{t}(4 ; 15)(\mathrm{q} 22.3 ; \mathrm{q} 21.3)$ associated with severe obesity. Eur. J. Hum. Genet. 13, 928-934.

Kodama, K., Horikoshi, M., Toda, K., Yamada, S., Hara, K., Irie, J., et al. (2012). Expression-based genome-wide association study links the receptor CD44 in adipose tissue with type 2 diabetes. Proc. Natl. Acad. Sci. U.S.A. 109, 70497054.

Kurebayashi, S., Ueda, E., Sakaue, M., Patel, D. D., Medvedev, A., Zhang, F., et al. (2000). Retinoid-related orphan receptor $\gamma(\operatorname{ROR} \gamma)$ is essential for lymphoid organogenesis and controls apoptosis during thymopoiesis. Proc. Natl. Acad. Sci. U.S.A. 97, 1013210137.

Lau, P., Fitzsimmons, R. L., Pearen, M. A., Watt, M. J., and Muscat, G. E. (2011). Homozygous staggerer $(\mathrm{sg} / \mathrm{sg})$ mice display improved insulin sensitivity and enhanced glucose uptake in skeletal muscle. Diabetologia 54, 1169-1180.

Lau, P., Fitzsimmons, R. L., Raichur, S., Wang, S. C., Lechtken, A., and Muscat, G. E. (2008). The orphan nuclear receptor, $\mathrm{ROR} \alpha$, regulates gene expression that controls lipid metabolism: staggerer (SG/SG) mice are resistant to diet-induced obesity. J. Biol. Chem. 283, 1841118421.

Logan, R. W., and Sarkar, D. K. (2012). Circadian nature of immune function. Mol. Cell. Endocrinol. 349, 82-90.

Maury, E., Ramsey, K. M., and Bass, J. (2010). Circadian rhythms and metabolic syndrome: from experimental genetics to human disease. Circ. Res. 106, 447-462.

Meissburger, B., Ukropec, J., Roeder, E., Beaton, N., Geiger, M., Teupser, D., et al. (2011). Adipogenesis and insulin sensitivity in obesity are regulated by retinoid-related orphan receptor $\gamma$. EMBO Mol. Med. 3, 637-651.

Mohawk, J. A., Green, C. B., and Takahashi, J. S. (2012). Central and peripheral circadian clocks in mammals. Annu. Rev. Neurosci. 35, 445462.

Mongrain, V., Ruan, X., Dardente, H., Fortier, E. E., and Cermakian, N. (2008). Clock-dependent and independent transcriptional control of the two isoforms from the mouse ROR $\gamma$ gene. Genes Cells 13, 11971210.

Mühlbauer, E., Bazwinsky-Wutschke, I., Wolgast, S., Labucay, K., and Peschke, 
E. (2013). Differential and daytime dependent expression of nuclear receptors $\mathrm{ROR} \alpha, \mathrm{ROR} \beta, \mathrm{ROR} \gamma$ and $\operatorname{RXR} \alpha$ in the rodent pancreas and islet. Mol. Cell. Endocrinol. 365, 129-138.

Narasimamurthy, R., Hatori, M., Nayak, S. K., Liu, F., Panda, S., and Verma, I. M. (2012). Circadian clock protein cryptochrome regulates the expression of proinflammatory cytokines. Proc. Natl. Acad. Sci. U.S.A. 109, 12662-12667.

Nishimura, S., Manabe, I., Nagasaki, M., Eto, K., Yamashita, H., Ohsugi, M., et al. (2009). CD8+ effector T cells contribute to macrophage recruitment and adipose tissue inflammation in obesity. Nat. Med. 15, 914-920.

Nomiyama, T., Perez-Tilve, D., Ogawa, D., Gizard, F., Zhao, Y., Heywood, E. B., et al. (2007). Osteopontin mediates obesity-induced adipose tissue macrophage infiltration and insulin resistance in mice. J. Clin. Invest. 117, 2877-2888.

Odegaard, J. I., and Chawla, A. (2008). Mechanisms of macrophage activation in obesity-induced insulin resistance. Nat. Clin. Pract. Endocrinol. Metab. 4, 619-626.

Ogden, C. L., Carroll, M. D., Kit, B. K., and Flegal, K. M. (2012). Prevalence of obesity and trends in body mass index among US children and adolescents, 1999-2010. JAMA 307, 483-490.

Ohoka, N., Kato, S., Takahashi, Y., Hayashi, H., and Sato, R. (2009). The orphan nuclear receptor ROR $\alpha$ restrains adipocyte differentiation through a reduction of $C / E B P \beta$ activity and perilipin gene expression. Mol. Endocrinol. 23, 759-771.

Ouchi, N., Parker, J. L., Lugus, J. J., and Walsh, K. (2011). Adipokines in inflammation and metabolic disease. Nat. Rev. Immunol. 11, 85-97.

Raichur, S., Lau, P., Staels, B., and Muscat, G. E. (2007). Retinoid-related orphan receptor $\gamma$ regulates several genes that control metabolism in skeletal muscle cells: links to modulation of reactive oxygen species production. J. Mol. Endocrinol. 39, 29-44.

Ramasamy, A., Kuokkanen, M., Vedantam, S., Gajdos, Z. K., Couto Alves, A., Lyon, H. N., et al. (2012). Genome-wide association studies of asthma in population-based cohorts confirm known and suggested loci and identify an additional association near HLA. PLoS ONE 7:e44008. doi: 10.1371/journal.pone.0044008

Raspe, E., Duez, H., Gervois, P., Fievet, C., Fruchart, J. C., Besnard, S., et al. (2001). Transcriptional regulation of apolipoprotein C-III gene expression by the orphan nuclear receptor ROR $\alpha$. J. Biol. Chem. 276, 28652871.

Rose, A. J., and Richter, E. A. (2005). Skeletal muscle glucose uptake during exercise: how is it regulated? Physiology (Bethesda) 20, 260-270.

Rudic, R. D., McNamara, P., Curtis, A. M., Boston, R. C., Panda, S., Hogenesch, J. B., et al. (2004). BMAL1 and CLOCK, two essential components of the circadian clock, are involved in glucose homeostasis. PLoS Biol. 2:e377. doi: 10.1371/journal.pbio.0020377

Saltiel, A. R., and Kahn, C. R. (2001) Insulin signalling and the regulation of glucose and lipid metabolism. Nature 414, 799-806.

Samuel, V. T., and Shulman, G. I. (2012). Mechanisms for insulin resistance: common threads and missing links. Cell 148, 852-871.

Sato, T. K., Panda, S., Miraglia, L. J., Reyes, T. M., Rudic, R. D. McNamara, P., etal. (2004). A functional genomics strategy reveals Rora as a component of the mammalian circadian clock. Neuron 43 , 527-537.

Solt, L. A., and Burris, T. P. (2012). Action of RORs and their ligands in (patho)physiology. Trends Endocrinol. Metab. 23, 619-627.

Solt, L. A., Griffin, P. R., and Burris, T. P. (2010). Ligand regulation of retinoic acid receptor-related orphan receptors: implications for development of novel therapeutics. Curr. Opin. Lipidol. 21, 204-211.

Solt, L. A., Kumar, N., Nuhant, P., Wang, Y., Lauer, J. L., Liu, J., et al. (2011). Suppression of TH17 differentiation and autoimmunity by a synthetic ROR ligand. Nature 472, 491-494.

Somm, E., Cettour-Rose, P., Asensio, C., Charollais, A., Klein, M., TheanderCarrillo, C., et al. (2006). Interleukin1 receptor antagonist is upregulated during diet-induced obesity and regulates insulin sensitivity in rodents. Diabetologia 49, 387-393.

Stehlin-Gaon, C., Willmann, D., Zeyer, D., Sanglier, S., Van Dorsselaer, A., Renaud, J. P., et al. (2003). All-trans retinoic acid is a ligand for the orphan nuclear receptor ROR $\beta$. Nat. Struct. Biol. 10, 820-825.

Sun, K., Kusminski, C. M., and Scherer, P. E. (2011). Adipose tissue remodeling and obesity. J. Clin. Invest. 121, 2094-2101.

Sun, Z., and Lazar, M. A. (2013). Dissociating fatty liver and diabetes. Trends Endocrinol. Metab. 24, 4-12.

Sun, Z., Unutmaz, D., Zou, Y. R., Sunshine, M. J., Pierani, A., BrennerMorton, S., et al. (2000). Requirement for ROR $\gamma$ in thymocyte survival and lymphoid organ development. Science 288, 2369-2373.

Takeda, Y., Jothi, R., Birault, V., and Jetten, A. M. (2012). ROR $\gamma$ directly regulates the circadian expression of clock genes and downstream targets in vivo. Nucleic Acids Res. 40, 8519 8539.

Takeda, Y., Kang, H. S., Angers, M., and Jetten, A. M. (2011). Retinoic acidrelated orphan receptor $\gamma$ directly regulates neuronal PAS domain protein 2 transcription in vivo. Nucleic Acids Res. 39, 4769-4782.

Tilley, S. L., Jaradat, M., Stapleton, C., Dixon, D., Hua, X., Erikson, C. J. et al. (2007). Retinoid-related orphan receptor $\gamma$ controls immunoglobulin production and Th1/Th2 cytokine balance in the adaptive immune response to allergen. J. Immunol. 178, 3208-3218.

Tinahones, F. J., Moreno-Santos, I., Vendrell, J., Chacon, M. R., GarridoSanchez, L., Garcia-Fuentes, E., et al. (2012). The retinoic acid receptorrelated orphan nuclear receptor $\gamma 1$ $(\operatorname{ROR} \gamma 1)$ : a novel player determinant of insulin sensitivity in morbid obesity. Obesity 20, 488-497.

Ueda, H. R., Hayashi, S., Chen, W., Sano, M., Machida, M., Shigeyoshi, Y. et al. (2005). System-level identification of transcriptional circuits underlying mammalian circadian clocks. Nat. Genet. 37, 187-192.

Wang, Y., Kumar, N., Crumbley, C., Griffin, P. R., and Burris, T. P. (2010a). A second class of nuclear receptors for oxysterols: regulation of ROR $\alpha$ and $\operatorname{ROR} \gamma$ activity by 24S-hydroxycholesterol (cerebrosterol). Biochim. Biophys. Acta 1801, 917-923.

Wang, Y., Kumar, N., Solt, L. A. Richardson, T. I., Helvering, L. M. Crumbley, C., et al. (2010b). Modulation of retinoic acid receptor-related orphan receptor $\alpha$ and $\gamma$ activity by 7-oxygenated sterol ligands. J. Biol. Chem. 285, 5013-5025.
Wang, Y., Solt, L. A., and Burris, T. P. (2010c). Regulation of FGF21 expression and secretion by retinoic acid receptor-related orphan receptor $\alpha$. J. Biol. Chem. 285, 15668-15673.

Weisberg, S. P., McCann, D., Desai, M., Rosenbaum, M., Leibel, R. L., and Ferrante, A. W. Jr. (2003). Obesity is associated with macrophage accumulation in adipose tissue. J. Clin. Invest. 112, 1796-1808.

Xu, T., Wang, X., Zhong, B., Nurieva, R. I., Ding, S., and Dong, C. (2011). Ursolic acid suppresses interleukin17 (IL-17) production by selectively antagonizing the function of ROR $\gamma \mathrm{t}$ protein. J. Biol. Chem. 286, 2270722710.

Yang, X. O., Pappu, B. P., Nurieva, R., Akimzhanov, A., Kang, H. S., Chung, Y., et al. (2008). T helper 17 lineage differentiation is programmed by orphan nuclear receptors ROR $\alpha$ and ROR $\gamma$. Immunity 28, 29-39.

Zhang, E.E., Liu, Y., Dentin, R., Pongsawakul, P.Y., Liu, A. C., Hirota, T., et al. (2010). Cryptochrome mediates circadian regulation of cAMP signaling and hepatic gluconeogenesis. Nat. Med. 16, 1152-1156.

Conflict of Interest Statement: The authors declare that the research was conducted in the absence of any commercial or financial relationships that could be construed as a potential conflict of interest.

Received: 30 November 2012; paper pending published: 21 December 2012; accepted: 05 January 2013; published online: 25 January 2013.

Citation: Jetten AM, Kang HS and Takeda $Y$ (2013) Retinoic acid-related orphan receptors $\alpha$ and $\gamma$ : key regulators of lipid/glucose metabolism, inflammation, and insulin sensitivity. Front. Endocrin. 4:1. doi: 10.3389/fendo.2013.00001 This article was submitted to Frontiers in Diabetes, a specialty of Frontiers in Endocrinology.

Copyright () 2013 Jetten, Kang and Takeda. This is an open-access article distributed under the terms of the Creative Commons Attribution License, which permits use, distribution and reproduction in other forums, provided the original authors and source are credited and subject to any copyright notices concerning any third-party graphics etc. 